\title{
Chitosan-based nanomaterials on controlled bioactive agents delivery: a review
}

\begin{abstract}
This paper presents fundamental aspects related to the biopolymer chitosan, describing briefly the main chemical and structural characteristics that confer it its striking properties, especially those related to their bioactivity. Subsequently, some of the most common methods for the preparation of nanomaterials based on this biopolymer are summarized and briefly outlined some of its applications in the controlled release of biologically active agents. Exposed material allows have a general vision on the new and potential applications on controlled drug released that continue appearing for the chitosan and its derivatives - that seem to have no limits-in spite of having been on the scene for a long time.
\end{abstract}

Keywords: nanomaterials, drug controlled release, nanoparticles preparation, bioactive agents, nanotherapy
Volume 7 Issue 4 - 2018

\author{
Cristóbal Lárez Velásquez \\ Departamento de Química, Universidad de Los Andes, \\ Venezuela
}

Correspondence: Cristóbal Lárez Velásquez, Grupo de Polímeros, Departamento de Química, Facultad de Ciencias, Universidad de Los Andes, Mérida 5I0I,Venezuela, Email clarez@ula.ve

Received: July 27, 2017 | Published: August 28, 2018

\section{Introduction}

Materials constituted from structural units of matter whose linear dimensions oscillate between 1-100 $\mathrm{nm}$ are considered as nanomaterials (NMs) and the structural units that constitute them as nano-particles (NPs). NMs can be classified as: ${ }^{1}$ (a) compact nanomaterials, also known as nanostructured materials, ${ }^{2}$ whose structural elements (clusters, crystallites, molecules) have nanometric dimensions; they are generally isotropic in their macroscopic composition but are made up of nanometric size units that remain in contact and that constitute the repetitive structural elements; ${ }^{3}$ (b) nanodispersions, formed by nanometric structural elements that remain scattered in a medium (vacuum, gas, liquid, solid) and isolated from each other; the distance between nanometric units in such dispersions can vary between wide limits, from fractions of one to tens of nanometers.

One of the most interesting aspects of NMs is that they usually exhibit properties that depend to a large extent on the size and shape of their nanoestructural constituents and whose properties generally differ markedly from those shown by the same massive conventional material, which appears as a continuous mass. Thus, NMs have generated a lot of interest for their potential applications in various scientific and technological fields.

Another important characteristic of NMs is the great diversity of substances that can be used for their formation, including metallic elements, crystals, macromolecules, etc., whose choice will depend, obviously, on the type of application that is intended to be given. In the case of applications that consider aspects such as biological activities, the biopolymer known as chitosan, or any of their numerous reported modifications, has widely excelled as starting material for the formulation of NMs because it has striking properties for such purposes, such as for example biocompatibility, ${ }^{4}$ low toxicity tested in animals ${ }^{5}$ and humans, ${ }^{6}$ bio- and muco-adhesibity, ${ }^{7}$ biodegradability, ${ }^{8}$ among others. Many of the biological properties of chitosan and its relationship with their physicochemical properties have been described in books and literature reviews on the subject. ${ }^{9-15}$

In this work the fundamental details related to chitosan are briefly presented, describing the main chemical and structural characteristics that give it its recognized properties, especially those related to their bioactivity. The most common methods for the preparation of NMs based on this biopolymer are summarized and some of their applications in the controlled release of biologically active agents are briefly outlined. The discussed material allows have a panoramic vision on the new and potential applications that continue appearing for the chitosan and its derivatives -that seem to have no limits- in spite of having been on the scene for a long time.

\section{Chitosan}

Chitosan is actually a polysaccharide rather know. It can be considered a lineal copolymer of glucosamine and $\mathrm{N}$-acetyl-glucosamine and it is generally named as poly ( $\beta-1,4$-glucosamine-co-N-acetyl- $\beta-1,4-$ glucosamine). Although it is naturally present in some fungi, especially of the Mucor species, its main source of production is the chemical deacetylation of chitin or poly (N-acetyl-1,4-glucosamine), a reaction that usually leads to a random distribution of acetylated (GlcNAc; $\beta-(1,4)$ 2-acetamido-2-deoxy-D-4-glucopyranose) and deacetylated (GlcN; $\beta$-(1,4)-2-amino-2-deoxy-D-glucopyranose) units along the chain, in proportions defined by a parameter known as degree of deacetylation (DD). DD represents the fraction of deacetylated units in the biopolymer chains and it usually ranges between $0.50-0.95$. Figure 1 allows clarifying this definition.

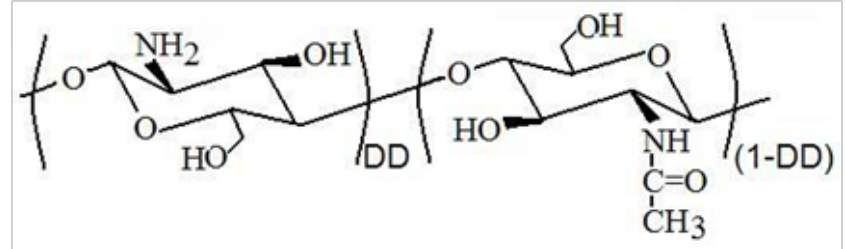

Figure I Constitutional repeating units in the chitosan polymer chains are usually randomly distributed along the chain. The deacetylated units represent the fraction defined as DD while the acetylated units represent the remaining fraction (I-DD).

The presence of the amine groups along the chain gives to this biopolymer its distinctive feature of other known polysaccharides (pectin, dextran, agarose, carrageenan, etc.), which exhibit acidic properties in aqueous solutions, while chitosan has a basic character due to the protonation of the amine group present in each of the glucosamine units. Similarly, it has been widely proposed that the chitosan biological activity derives, to a large extent, from the cationic character associated with said protonation $^{12,16}$ although it has been proven that hydrophobic interactions 
also play their role. ${ }^{17}$

Commercial chitosan generally appears in the form of flakes or as a powder of color between white and beige, whose glass transition temperature depends on the molecular weight, DD and the moisture content in the sample analyzed. On the other hand, the material is soluble in short-chain organic acids such as formic, lactic, acetic, tartaric, citric, etc., being an acetic acid $1 \%$ aqueous solution the solvent most commonly employed. Obtaining values of $\mathrm{pH}<6$ is fundamental for its dissolution in these systems. It is also soluble in $1 \%$ aqueous solutions of mineral acids such as hydrochloric acid and nitric acid but it is insoluble in sulfuric and phosphoric acids.

Chitosan has a series of properties that have allowed it to be proposed for a wide range of applications in multiple fields. Thus, for example, it can act as a thickener in foods because it forms highly viscous aqueous solutions, is mucoadhesive, forms polyelectrolyte complexes, has excellent filmogenic properties, acts as a chelating agent for many metals, has the potential to bind to microbial and mammals cells and, due to its regenerative effect, it is an excellent material for the preparation of scaffolds in tissue engineering as well as bone formation. Another of their appreciated biological properties, which are used commercially in agriculture, are its benefits as a stimulant of growth and inducer of defense mechanisms against phytopathogens, fungicide for the protection of seeds, post-harvest protection of fruits, etc. In dentistry and medicine it has also been used for the preparation of commercial materials in the treatment of haemorrhages and burns.

\section{Chitosan-based nanomaterials}

Due to the importance acquired by NMs and the increasing incorporation of chitosan in these systems -after the first preparation of chitosan nanospheres by Ohya et al., ${ }^{18}$ the issue has been subject to the necessary systematization by a large number of authors, a task not easy considering the complexity of the potential applications that have been proposed for these materials. Initial applications of the chitosan-based NMs focused practically towards the transport and controlled release of therapeutic agents. ${ }^{19-21}$ Recent reviews on the subject, some of which also include the most used preparation methods for these purposes, are those of Agnihotri et al., ${ }^{22}$ Goycoolea et al., ${ }^{23}$ Wang et al., ${ }^{24}$ Peniche et al, ${ }^{25}$ Elgadir et al., ${ }^{26}$ and Ali \& Amhed. ${ }^{27}$ Below are briefly described, in a general way, some of the most widespread. ${ }^{28}$

\section{Ionotropic gelation}

A typical procedure includes preparation of a diluted solution of chitosan in aqueous acid medium, in the order of approximately $1 \mathrm{mg} /$ $\mathrm{mL}$, which is added to an aqueous solution of a low molecular weight polyanion (with a concentration similar to the chitosan solution), under magnetic stirring, after which the NPs spontaneously form. Subsequently, the NPs can be separated by centrifugation. The most commonly employed polyanion is the pentasodium tripolyphosphate ${ }^{29-31}$ (TPP, structure I) although the preparation of NPs of chitosan also have been reported with other polyanions, i.e., adenosine triphosphate ${ }^{32}$ (ATP, structure II), trisodium citrate ${ }^{33}$ (structure III) and sodium sulfate. ${ }^{34}$

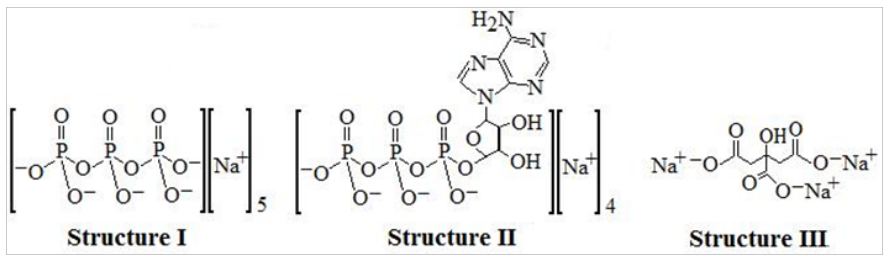

Citation: Velásquez CL. Chitosan-based nanomaterials on controlled bioactive agents delivery: a review.J Anal Pharm Res. 2018;7(4):484-489. DOI: 10.15406/japlr.2018.07.0027।

\section{Spraying/drying}

The general process involves the preparation of a chitosan solution in acidic aqueous medium, i.e., $0.5 \% \mathrm{v} / \mathrm{v}$ acetic acid in water, which is sprayed by means of an equipment designed for that purpose (homemade or commercial). The control of the size of the NPs can be achieved by varying the various parameters associated with the equipment, such as the size of the outlet nozzle of the solution, the flow velocity and the solution temperature, the flow velocity and the temperature of the drying gas, etc. Likewise, some properties related to chitosan play an important role such as the concentration of the solution used and the molecular weight of the sample empolyed..$^{35}$

\section{Coacervation/precipitation}

A procedure commonly used for the preparation of NPs by this route consists in dropping a determined volume of a solution of $\mathrm{Na}_{2} \mathrm{SO}_{4}$ of known concentration on a fixed volume of a solution of chitosan in aqueous acidic medium, of known concentration, under constant magnetic stirring during a previously established time, after which the coacervates are separated by filtration through membranes with pore diameters greater than $400 \mathrm{~nm}$. Among the parameters that must be controlled in this type of systems is the sulphate/amine molar ratio $\left(\mathrm{r}_{\mathrm{SA}}\right) .{ }^{36}$ There are some variations of this procedure that include the use of surfactants in the chitosan solution, the use of ultrasound during magnetic stirring, the separation of NPs by centrifugation, etc.

\section{Reverse emulsification}

A colloidal system with reverse micelles is first prepared using a surfactant in an organic solvent; an aqueous solution of chitosan is added to this system, with constant agitation to avoid the formation of turbidity. The size of NPs can be increased by adding additional amounts of water. After achieving the system stability, a covalent crosslinking agent is added and it is allowed to react for the necessary time with constant agitation. Subsequently, the organic solvent is evaporated to obtain a transparent dry mass, which is dispersed in water, followed by the addition of the appropriate salt to precipitate the surfactant. This is separated by centrifugation and the liquid supernatant phase containing the NPs is decanted, dialyzed and lyophilized. ${ }^{37}$ This method, apart from being tedious, has the disadvantage of using surfactants and organic solvents that make it difficult to purify the NPs obtained, a situation that can strongly limit it for applications related to the transport and release of therapeutic agents.

\section{Polyelectrolyte complexation}

Systems to produce this type of NPs can be very similar to that used in either ionotropic gelation, spraying/drying or coacervation with $\mathrm{Na}_{2} \mathrm{SO}_{4}$. The substantial difference with theses consists of the macromolecular nature of the employed polyanions in order to obtaining a polyelectrolyte complex (polyplexes), i.e., it can highlight the use of DNA to obtain this type of NMs.$^{38} \mathrm{~A}$ very important advantage of these systems is that they allow obtaining nanoparticles with positive or negative external charges, depending on which polyelectrolyte solution is allowed to drip on the solution of the other. Additionally, it is possible to construct NPs with a variable number of layers, which can be formed by alternating immersion of the initial NPs in the solutions of the polyelectrolytes of interest. Figure 2 shows a hypothetical molecular arrangement of both polyelectrolytes when drops of an aqueous solution of chitosan are dropped onto an aqueous solution containing a macromolecular polyanion. It is important to indicate that even when the initially formed spheres can exceed the nano scale, their size decreases considerably when they are thermally dried. 


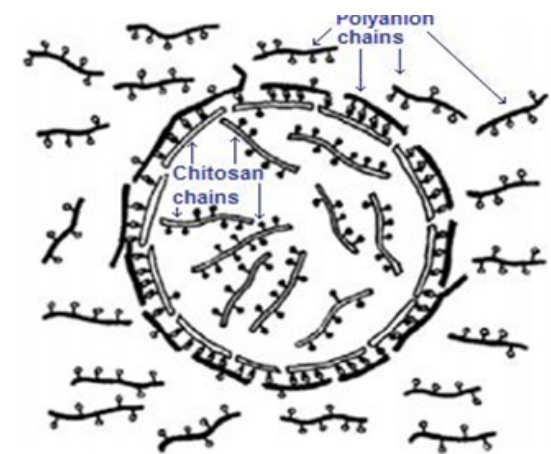

Figure 2A hypothetical macromolecular arrangement in the nanospheres formation through the process of polyelectrolyte complexation when a volume of a chitosan solution is dropped on a macromolecular polyanion solution. ${ }^{28}$

\section{Some system of chitosan-based NMs for controlled bioactive agents release}

Chitosan has strongly attracted attention in recent years for the preparation of drug carrier nanomaterials with applicability in the "smart" drug delivery because of their good bioadhesibilidad, biocompatibility and biodegradability properties. Additionally, this biopolymer can undergo a wide range of chemical modification reactions becoming more versatile yet. In this regard, numerous studies have been reported on the preparation of specific transport systems and effective delivery of different types of therapeutic agents, i.e., genes, proteins, hormones, etc. Also, the routes of administration that are being tested are diverse: oral, nasal, intravenous, ocular, etc. Table 1 presents a brief list of studies that have recently been reported on this subject. Subsequently, a short discussion of some release systems that have been tested is presented. ${ }^{39-44}$

Table I Some recently reported studies on the transport and effective delivery of therapeutic agents using chitosan-based NMs

\begin{tabular}{|c|c|c|}
\hline Agent & Nanomaterial system & Observations \\
\hline $\begin{array}{l}\text { Small interfering RNA } \\
\text { (si-RNA) }\end{array}$ & $\begin{array}{l}\text { PEGylated chitosan-based NPs obtained } \\
\text { by ionotropic gelation with TPP }\end{array}$ & $\begin{array}{l}\text { NPs that achieve high gene silencing in vitro, low cytotoxicity and high stability } \\
\text { in plasma could be promising for intravenous delivery of siRNA. }{ }^{39}\end{array}$ \\
\hline $\begin{array}{l}\text { DNA vaccine for } \\
\text { Hepatitis B virus } \\
\text { (HBV) }\end{array}$ & $\begin{array}{l}\text { Human serum albumin-loaded } \\
\text { chitosan NPs/DNA complexes }\end{array}$ & $\begin{array}{l}\text { A robust systemic immune response was induced after vaccination with this } \\
\text { complexes. }{ }^{40}\end{array}$ \\
\hline Insulin & $\begin{array}{l}\text { Insulin-chitosan NPs (ICNPs) obtained } \\
\text { by ionotropic gelation with TPP }\end{array}$ & $\begin{array}{l}\text { Insulin trapped in ICNPs was released slowly and }>93.0 \% \text { was released } \\
\text { completely within } 24 \mathrm{~h}^{41}\end{array}$ \\
\hline $\begin{array}{l}\text { Diclofenac sodium } \\
\text { (DS) }\end{array}$ & $\begin{array}{l}\text { DS-Trimethyl chitosan (TMC)-based NPs } \\
\text { obtained obtained by ionotropic gelation } \\
\text { with TPP }\end{array}$ & $\begin{array}{l}\text { DC-TMC NPs were safe for ophthalmic use. The in vivo absorption study on } \\
\text { rabbits indicated that could improve ophthalmic bioavailability of DC and } \\
\text { these had potential for use as an alternative to conventional DC eye drops. }{ }^{42}\end{array}$ \\
\hline $\begin{array}{l}\text { Human paratiro-idea } \\
\text { hormone (PTH I-34) }\end{array}$ & $\begin{array}{l}\text { NPs obtained by ionotropic gelation } \\
\text { with TPP of a PTH I-34/thiolated } \\
\text { chitosan solution. }\end{array}$ & $\begin{array}{l}\text { TSC-PTH I-34 NPs have released an advantageous anabolic dose of the } \\
\text { peptide in blood that is suited for the treatment of osteoporosis. }{ }^{43}\end{array}$ \\
\hline Piperine (PIP) & $\begin{array}{l}\text { NPs obtained by ionotropic gelation } \\
\text { with TPP of a PIP/chitosan solution. }\end{array}$ & $\begin{array}{l}\text { Mucoadhesive CS-NPs were successfully tailored for effective, safe, and } \\
\text { non-invasive PIP delivery with } 20 \text {-folds decrease in oral dose. } 44\end{array}$ \\
\hline
\end{tabular}

\section{Gene transfection}

Despite showing generally low efficiencies for genetic transfection, chitosan-based NMs seem to be able to take advantage of its ability to adhere to the cell walls due to the positive surface charges provided by the protonation of the chitosan amine groups. In this regard, studies of Lavertou et al., ${ }^{45}$ point out that the maximum of transgenetic expression occurs when the DD/molecular weight (MW) ratio goes from high DD/low MW up to low DD/high MW. These researchers tested some formulations of NPs (type chitosan/plasmid DNA polycomplex) particularly effectives, which have shown transfection efficiency values promisingly comparable to those obtained with the best known positive controls. On the other hand, the chemical modification of chitosan could be an alternative route for the generation of new NMs that allow achieving better results in the area, as it has been demonstrated by the modification of chitosan with folic acid and achieving in this way a cell viability of $80 \%$, which competes advantageously with $30 \%$ obtained for an usual transfection agent such as LipofectAMINE $2000 .{ }^{46}$

\section{Hormone release}

Estradiol is a potent sex hormone which has been used in the prevention and treatment of Alzheimer disease. It is of fundamental importance to achieve a sufficient tissue concentration of estradiol in the brain to observe its effect. When estradiol is administered alone, orally, their cerebrospinal levels result very low; however, these levels were found to be high compared to plasma levels when estradiol was administered intranasally as chitosan NPs, suggesting that estradiol is transported to the brain directly when it is transported through the nasal route as chitosan NPs ${ }^{47}$ Another promissory system based in polymeric-metallic hybrid nanoparticles coated with glycol chitosan has been proposed recently for progesterone controlled release. Kinetic studies carried out with it shown that release differ significantly with $\mathrm{pH}$ changes, where nanoparticles exhibited swelling at $\mathrm{pH} 6.5$ and shrinkage at $\mathrm{pH}$ 7.4. On the other hand, metabolic activity assay of $\mathrm{C} 3 \mathrm{H} 10 \mathrm{~T} 1 / 2$ cell line resulted in a promising biocompatibility of these magnetic nanoparticles. ${ }^{48}$

Regarding this topic, a special commentary should be made on the chitosan/tripolyphosphate-based nanosystems developed by Rather et al., ${ }^{49}$ for the sustained nanorelease of the hormone gonadotropin (obtained from salmon) in test fish (common carp), obtaining a fertilization 13\% higher than the injection of the hormone alone. In addition to the greater effectiveness of the system these results can also be considered a clear evidence of the protection that chitosan provides to the hormone, which is known to have a short half-life in the bloodstream.

\section{Protein release}

Medical and pharmaceutical studies related to protein release are very numerous due to the diversity of roles played by them. Table 2 shows some recent studies on protein delivery/release using chitosanbased NMs. As it can be seen proteins can act in some cases as an active 
therapeutic agent and in others their role can be that of signaling agent to direct the carrier to a specific target and/or enhancer of the cellular uptake of the bioactive agent-loaded Nps. Finally, it is important to stand out that most studies conducted with chitosan suggest that it ensures greater stability and protection of proteins from degradation during their transit through aggressive areas, as well as promote better contact with biomembranes, ensuring a greater bioavailability of these..$^{51-56}$

Table 2 Some recently reported studies on chitosan-based NMs for protein controlled delivery

\begin{tabular}{|c|c|c|c|}
\hline Released protein & Route/Essay & NPs preparation & Observations \\
\hline Human albumin & Oral and peritoneal & lonic gelation with TPP & $\begin{array}{l}\text { Sustained release over time, high enzymatic stability, inclusion into } \\
\text { acid-resistant capsules provided protection against harsh gastric } \\
\text { environment. }^{51}\end{array}$ \\
\hline Insulin & Oral & $\begin{array}{l}\text { Polyelectrolyte complexation } \\
\text { with poly ( } \gamma \text {-glutamic acid) }\end{array}$ & $\begin{array}{l}\text { Chitosan shelled NPs are promising vehicles for oral delivery } \\
\text { of insulin. However, these must demonstrate their superiority } \\
\text { over the injectable insulin in terms of better management } \\
\text { of the blood glucose level and lesser occurrence of diabetic } \\
\text { complications. Additionally, their long-term efficacy must be } \\
\text { demonstrated in large animals and in humans. } .^{52}\end{array}$ \\
\hline $\begin{array}{l}\text { Bone morpho- } \\
\text { genetic protein-2 } \\
\text { (BMP-2) }\end{array}$ & $\begin{array}{l}\text { Release studies carried } \\
\text { out in phosphate buffer } \\
\text { solutions }\end{array}$ & $\begin{array}{l}\text { Mesoporous silica NPs coated } \\
\text { with crosslinked chitosan }\end{array}$ & $\begin{array}{l}\text { NPs carrier demonstrates an enhanced co-loading capability } \\
\text { and persistent bioactivity of BMP- } 2 \text {.This dual-drug delivery } \\
\text { system displays enhanced osteoblast differentiation of bMSCs } \\
\text { cells in vitro and bone formation in vivo. } .^{53}\end{array}$ \\
\hline $\begin{array}{l}\text { Fluorescent } \\
\text { Ovoalbumin and } \\
\text { Concanavalin }\end{array}$ & $\begin{array}{l}\text { Release studies } \\
\text { carried out in water } \\
\text { and phosphate buffer } \\
\text { solutions }\end{array}$ & $\begin{array}{l}\text { NPs obtained by precipitation- } \\
\text { coacervation method using } \\
\text { different precipitation salts. }\end{array}$ & 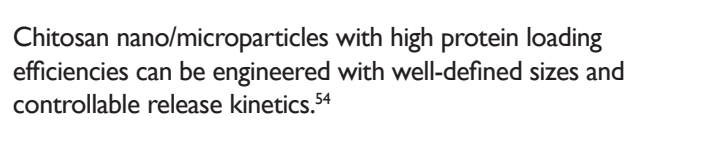 \\
\hline $\begin{array}{l}\text { Oxaliplatin and TRAIL } \\
\text { antibody }\end{array}$ & $\begin{array}{l}\text { Therapeutic activity } \\
\text { evaluated in vitro in } \\
\mathrm{HT}-29 \text { cell lines and in } \\
\text { vivo in xenograft tumor } \\
\text { models. }\end{array}$ & $\begin{array}{l}\text { Hybrid NMs obtained by load of } \\
\text { oxaliplatin and TRAIL antibody } \\
\text { in chitosan NPs and then coated } \\
\text { with lipid }\end{array}$ & $\begin{array}{l}\text { Drug/NMs were properly directed at the target by TRAIL } \\
\text { antibody protein, which was proven by the reducing of tumor } \\
\text { mass and tumor volume in xenograft tumor models in vivo along } \\
\text { with a sustained release in vitro. } .^{55}\end{array}$ \\
\hline $\begin{array}{l}\text { Curcumin }(C R) \text { and } \\
\text { transferrin }(T r)\end{array}$ & $\begin{array}{l}\text { In vitro anticancer } \\
\text { activity of CR loaded } \\
\text { Nps was studied by } \\
\text { Sulforhodamine B assay } \\
\text { using a Human Breast } \\
\text { Carcinoma cell line. }\end{array}$ & $\begin{array}{l}\text { Transferrin was covalently bound } \\
\text { on the surface of curcuma- } \\
\text { loaded Nps using EDC coupling. }\end{array}$ & $\begin{array}{l}\text { Drug/NMs were properly directed at the target by transferrin, } \\
\text { which also enhanced the cellular uptake of curcumin carrying } \\
\text { Nps. }{ }^{56}\end{array}$ \\
\hline
\end{tabular}

\section{Future trends}

Although chitosan has been widely used as the cationic macromolecular counterpart in the various methods used to prepare $\mathrm{MNs}$, it is also possible to use its cationic oligomers as salts whose solutions are dropped into a solution of a macromolecular polyanion, i.e., these oligomeric chitosan salts would play the role of TPP in traditional systems (ionotropic gelation) or sulfates (coacervation/ precipitation). This type of systems has been little studied but could expand even more the field of NMs based on chitosan, especially if oligomeric N-trimethyl-chitosan salts are considered because their cationic charges are not $\mathrm{pH}$ dependent.

On the other hand, chitosan has been widely used for the delivery and release of bioactive substances but not for entrapment and/or collection of substances at specific sites. In this sense, it is possible to formulate NPs that absorb a specific molecule to remove it from circulation in a protected manner. An example could be the preparation of chitosan specific nanoabsorbents for intoxicants, similar to absorbent molecularly impressed prepared to selectively adsorb methyl ricinoleate, ${ }^{57}$ which could be rapidly supplied via oral as a highly selective absorbent to mask the intoxicant before it has harmful effects, i.e., intoxication by ingestion of a very high dose of acetaminophen, which is relatively frequent in young children due to the flavorings and sweeteners that are used in this type of medicaments.
In spite the potential advantages that can be glimpsed for these chitosan-based NMs, and in general for all NMs, it is necessary to strongly emphasize that their long term effects on human health and environment are little known. Therefore, it is essential that biosecurity plays a leading role in the development of these systems nanobiotechnologycs. ${ }^{58}$ Similarly, much work remains to be done on the education, communication, ethics and legal aspects of the NMs.

\section{Conclusion}

The potentialities of nanomaterials based on chitosan-and their derivatives-seem to be becoming more numerous every day, especially in the field of delivery and controlled release of bioactive agents. Protein controlled delivery/release seems to be currently one of the most promising areas to obtain achievements in the treatment of diseases such as cancer, especially because they can be used favorably in different roles. Especially important in these cases has been the advancement of other areas of nanoscience and nanotechnology which has allowed obtaining increasingly pure materials and better analysis techniques, either from prepared nanomaterials as well as from results obtained when these are employed during in vitro and in vivo studies.

However, some initially promising areas, such as gene transfection using chitosan as a non-viral vector, have not yet managed to satisfy the expectations created. In the other hand, the studies on side effects of many 
hybrid nanomaterials look far away when it is known that reliable data from studies with simpler nanomaterials are not yet available. Likewise, it is necessary to streamline studies of the long-term effects of nanosystems on human health and environment. Education of user communities, creation of legal regulations in the countries and its communication to citizens, among other aspects, is a practically virgin field to work.

\section{Acknowledgements}

None.

\section{Conflict of interest}

The author declares that there is no conflict of interest.

\section{References}

1. Gubin S. Magnetic Nanoparticles. Wiley-VCH Verlag GmbH \& Co. KGaA. Alemania. 2009

2. Moriarty P. Nanostructured materials. Rep Prog Phys. 2001;64:297381.

3. Gusev A, Rampel A. Nanokristallicheskie Materialy (Nanocrystalline Materials). Fizmatlit.2001.

4. Rodrigues S, Dionísio M, Remuñán López C, et al. Biocompatibility of Chitosan Carriers with Application in Drug Delivery. Journal of Functional Biomaterials. 2012;3(3):615-641.

5. Rao S, Sharma C. Use of chitosan as a biomaterial: studies on its safety and hemostatic potential. Mater Res. 1997:34(1):21-28.

6. Aspden T, Mason J, Jones N, et al. Chitosan as a nasal delivery system: The effect of chitosan solutions on in vitro and in vivo mucociliary transport rates in human turbinates and volunteers. J Pharm Sci. 1997;86(4):509-513.

7. Mertins O, Dimova R. Insights on the interactions of chitosan with phospholipid vesicles. Part I: Effect of polymer deprotonation. Langmuir. 2013;29(47):14545-14551.

8. Tian Y, Sun Y, Wang X, et al. Chitosan and its derivatives-based nanoformulations in drug delivery. Nanobiomaterials in Drug Delivery. 2016;9:515-572.

9. Pastor A. Quitina y Quitosano. Obtención, Caracterización y Aplicaciones. Pontificia Universidad Católica del Perú, Perú; 2004.

10. Chalonglarp T, Sorada K, Neeracha S, et al. The influence of molecular weight of chitosan on the physical and biological properties of collagen/ chitosan scaffolds. J Biomater Sci Polym Ed. 2007;18(2):147-163.

11. Rinaudo M. Chitin and chitosan: Properties and applications. Prog Polym Sci. 2007;31(7):603-632.

12. C Lárez-Velásquez. Algunas potencialidades de la quitina y el quitosano para usos relacionados con la agricultura en Latinoamérica. Rev UDO-Agrícola. 2008;8(1):1-22.

13. New N, Furuike T, Tamu H. The Mechanical and Biological Properties of Chitosan Scaffolds for Tissue Regeneration Templates Are Significantly Enhanced by Chitosan from Gongronella butleri. Materials. 2009;2(2):374-398.

14. Cunha T, Teixeira B, Santos B. Biological and Pharmacological Activity of Chitosan and Derivatives. Chitosan-Based Systems for Biopharmaceuticals: Delivery, Targeting and Polymer Therapeutics. UK; John Wiley \& Sons, 2012.

15. Ahmed S, Ikram S. Chitosan \& Its Derivatives: A Review in Recent Innovations. Int J Pharm Sci Res. 2015;6(1):14-30.

16. Devlieghere F, Vermeulen A, Debevere J. Chitosan: antimicrobial activity, interactions with food components and applicability as a coating on fruit and vegetables. Food Microbiology. 2004;21:703-714.

17. Pavinatto A, Pavinatto F, Barros-Timmons A. Electrostatic interactions are not sufficient to account for chitosan bioactivity. ACS Applied Materials \& Interfaces. 2009;2(1): 246-251.

18. Ohya Y, Shiratani M, Kobayashi $\mathrm{H}$, et al. Release behaviour of 5fluorouracil from chitosan-gel nanospheres immobilizing 5-fluorouracil coated with polysaccharides and their cell specific cytotoxicity. Pure Appl Chem. 1994;A31:629-642.

19. Mao H, Roy K, Walsh S, et al. DNA-chitosan nanospheres for gene delivery. Proc Int Symp Control Rel Bioact Mater. 1996;23(9):401-402.

20. Calvo P, Remunan-Lopez C, Vila-Jato J, et al. Novel hydrophilic chitosan-poly-ethylene oxide nanoparticles as protein carrier. $J$ Appl Poly Sci. 1997;63(1):125-132.

21. Tian X, Groves M. Formulation and biological activity of antineoplastic proteo-glycans derived from Mycobacterium vaccae in chitosan nanoparticles. J Pharm Pharmacol. 1999;51(2):151-157.

22. Agnihotri S, Mallikarjuna N, Aminabhavi T. Recent advances on chitosan-based micro- and nanoparticles in drug delivery. $J$ Con Release. 2004;100(1):5-28.

23. Goycoolea-Valencia F, Remuñán López C, Alonso M. Nanopartículas a base de polisacáridos: quitosano. Nanotecnología Farmacéutica: Realidades y posibilidades farmacoterapéuticas. Real Academia Nacional de Farmacia. España. 2009:103-131.

24. Wang J, Zeng Z, Xia R, et al. Recent advances of chitosan nanoparticles as drug carriers. Int $J$ Nanomedicine. 2011;6:765-774.

25. Peniche H, Peniche C. Chitosan nanoparticles: a contribution to nanomedicine. Polym Int. 2011;60:883-889.

26. Elgadir M, Uddin M, Ferdosh $\mathrm{S}$, et al. Impact of chitosan composites and chitosan nanoparticle composites on various drug delivery systems: A review. J Food and Drug Analysis. 2015;23(4):619-629.

27. Ali, A, Ahmed S. A review on chitosan and its nanocomposites in drug delivery. Inter J BiolMacromo. 2018;109:273-286.

28. Lárez-Velásquez C. Quitosano y nanopartículas. Nanoparticulas: fundamentos y aplicaciones. Comisión de Publicaciones del Departamento de Química, Universidad de Los Andes, Venezuela. 2015:203-222.

29. Nasti A, Zaki N, Leonardis P, et al. Chitosan/TPP and chitosan/ TPP-hyaluronic acid nanoparticles: systematic optimization of the preparative process and preliminary biological evaluation. Pharm Res. 2009;26(8):1918-1930.

30. Lin A, Liu Y, Ping Q. Free amino groups on the surface of chitosan nanoparticles and its characteristics. Yао Хие Хие Вао. 2007;42(3):323328.

31. da Silva-Barbi M, Chiva-Carvalho F, Charlene-Kiill P, et al. Preparation and Characterization of Chitosan Nanoparticles for Zidovudine Nasal Delivery. J Nanosc Nanotech. 2015;15(1):865-874.

32. Majedi F, Hasani-Sadrabadi M, Emami S, et al. Microfluidic synthesis of chitosan-based nanoparticles for fuel cell applications. Chem Commun. 2012;48(62):1359-7345.

33. Ji J, Hao S, Dong J, et al. Preparation of Chitosan/Cyclodextrin/ Trisodium Citrate Nanoparticles for the Poor-Water Drug Carrier Material. Adv Mat Res. 2010;152-153.

34. Al-Remawi M. Properties of Chitosan Nanoparticles Formed Using Sulfate Anions as Crosslinking Bridges. Amer J App Sci. 2012;9(7):1091-1100.

35. Kim L, Wang S, Hiep D, et al. Preparation of chitosan nanoparticles by spray drying, and their antibacterial activity. Research on Chemical 
Intermediates. 2014;40(6):2165-2175.

36. Tavares I, Caroni A, Neto A, et al. Surface charging and dimensions of chitosan coacervated nanoparticles. Coll Surf B. 2012;90:254-258.

37. Mitra S, Gaur U, Ghosh P, et al. Tumour targeted delivery of encapsulated dextran-doxorubicin conjugate using chitosan nanoparticles as carrier. $J$ Control Release. 2001;74(1-3):317-323.

38. Agirre M, Zarate J, Ojeda E, et al. Low Molecular Weight Chitosan (LMWC)-based Polyplexes for pDNA Delivery: From Bench to Bedside. Polymers. 2014;6:1727-1755.

39. Ragelle H, Riva R, Vandermeulen G, et al. Chitosan nanoparticles for siRNA delivery: optimizing formulation to increase stability and efficiency. J Controlled Release. 2014;176:54-63.

40. Lebre F, Borchard G, Faneca H, et al. Intranasal administration of novel chitosan nanoparticle/DNA complexes induces antibody response to hepatitis B surface antigen in mice. Molecular Pharmaceutics. 2016;13(2):472-482.

41. Zhao L, Su C, Zhu B, et al. Development and Optimization of InsulinChitosan Nanoparticles. Trop J Pharm Res. 2014:13(1):3-8.

42. Asasutjarit R, Theerachayanan T, Kewsuwan P, et al. Development and evaluation of diclofenac sodium loaded-N-Trimethyl chitosan nanoparticles for ophthalmic use. AAPS PharmSciTech. 2015;16(5):1013-1024.

43. Narayanan D, Anitha A, Jayakumar R, et al. PTH 1-34 loaded thiolated chitosan nanoparticles for osteoporosis: oral bioavailability and anabolic effect on primary osteoblast cells. J Biomed Nanotechnol. 2014;10(1):166-178.

44. Elnaggar Y, Etman S, Abdelmonsif D, et al. Intranasal Piperine-Loaded Chitosan Nanoparticles as Brain-Targeted Therapy in Alzheimer's Disease: Optimization, Biological Efficacy, and Potential Toxicity. J Pharm Sci. 2015;104(10):3544-3556.

45. Lavertu M, Methot S, Trankhanh N, et al. High efficiency gene transfer using chitosan/DNA nanoparticles with specific combinations of molecular weight and degree of deacetylation. Biomaterials. 2006;27(27):4815-4824.

46. Mansouri S, Cuie Y, Winnik F, et al. Characterization of folate chitosanDNA nanoparticles for gene therapy. Biomaterials. 2006;27(9):20602065

47. Wang X, Chi N, Tang X. Preparation of estradiol chitosan nanoparticles for improving nasal absorption and brain targeting. Eur J. Pharm.
Biopharm. 2008;70:735-740.

48. Leena M, Doaa R, Shigang L, et al. Preparation and Characterization of Glycol Chitosan- $\mathrm{Fe}_{3} \mathrm{O}_{4}$ Core-Shell Magnetic Nanoparticles for Controlled Delivery of Progesterone. J Biomat Tiss Engin. 2017;7(7):561-570.

49. Rather M, Sharma R, Gupta S, et al. Chitosan-Nanoconjugated Hormone Nanoparticles for Sustained Surge of Gonadotropins and Enhanced Reproductive Output in Female Fish. PLoS ONE. 2013;8(2):e57094.

50. Amidi M, Mastrobattista E, Jiskoot W, et al. Chitosan-based delivery systems for protein therapeutics and antigens. Adv Drug Deliv Rev. 2010;62(1):59-82.

51. Nashaat D, Elsabahy M, El-Sherif T, et al. Development and in vivo Evaluation of Chitosan Nanoparticles for the Oral Delivery of Albumin. Pharm Develop Technol. 2018.

52. Sun H, Sonaje K, Z Liao, et al. pH-Responsive Nanoparticles Shelled with Chitosan for Oral Delivery of Insulin: From Mechanism to Therapeutic Applications. Acc Chem Res. 2012;45(4):619-629.

53. Gan Q, Zhu J, Yuan Y, et al. A dual-delivery system of pH-responsive chitosan-functionalized mesoporous silica nanoparticles bearing BMP-2 and dexamethasone for enhanced bone regeneration. $J$ Mater Chem B. 2014;3:2056-2066.

54. Prasanth Koppolu B, Smith S, Ravindranathan S, et al. Controlling chitosan-based encapsulation for protein and vaccine delivery. Biomaterials. 2014;35(14):4382-4389.

55. Tummala S, Gowthamarajan K, Satish Kumar M, et al. Oxaliplatin immuno hybrid nanoparticles for active targeting: an approach for enhanced apoptotic activity and drug delivery to colorectal tumors. Drug Delivery. 2016;23(5):1773-1787.

56. Sutar YB, Telvekar V. Chitosan based copolymer-drug conjugate and its protein targeted polyelectrolyte complex nanoparticles to enhance the efficiency and specificity of low potency anticancer agent. Mat Sci Eng C. 2018;92:393-406.

57. Rangel G, Comoy C, Santos I. Síntesis de un hidrogel basado en quitosano para la adsorción selectiva de ricinoleato de metilo. XVI Coloquio Venezolano de Polímeros. Venezuela 2015.

58. Rocha-Salvarrieta P. Nanobiotecnologíaa y sus potenciales aplicaciones en agricultura. Nanoparticulas: fundamentos y aplicaciones. Comisión de Publicaciones del Departamento de Química, Universidad de Los Andes, Venezuela. 2015:223-244. 